\title{
Re-composición de la ruralidad en el imaginario urbano: el caso de las quebradas de Valparaíso ${ }^{1}$ \\ ANDREA PINO VÁSQUEZ \\ > Departamento de Arquitectura, Universidad Técnica Federico Santa María. andreapino.v@hotmail.com
}

Universidad de Valparaíso

Facultad de Arquitectura

Revista Márgenes

Espacio Arte Sociedad

Re-composición de la ruralidad en el imaginario urbano:

el caso de las quebradas de Valparaíso

Diciembre 2013 Vol. 10 № 13

Páginas 49 a 61

ISSN elec. 0719-4463

ISSN imp. 0718-4034

Recepción: Agosto 2013

Aceptación: Noviembre 2013

\section{RESUMEN}

Esta investigación tiene por objetivo develar y evidenciar los procesos socio espaciales ligados a la instauración, recomposición y consolidación de la ruralidad en el hábitat informal presente en las quebradas de Valparaíso exponiendo las representaciones sociales que poseen sus habitantes. Las quebradas de Valparaíso en tanto que unidades urbanas se constituyen como una realidad socio espacial compleja, que alberga un conjunto de significaciones, representaciones e imaginarios sociales asociados a la ruralidad.

Para entender las lógicas de este tipo de apropiación del espacio en las quebradas (tomas ilegales de terreno) se recurrió a sus actores principales, "sus habitantes", quienes evidenciaron y revelaron desde sus experiencias vividas, sus expectativas y sus proyectos a venir, esta recomposición imaginaria de la ruralidad en el espacio urbano.

PALABRAS CLAVE

ruralidad, quebradas, informalidad, imaginario

\section{Re-composition of rural life in the urban imaginary: the case of the quebradas of Valparaíso \\ ABSTRACT}

This research aims to uncover and reveal socio-spatial processes linked to the establishment, rearrangement and consolidation of rural life in the informal habitat present in the quebradas of Valparaiso exposing social representations that its inhabitants have. The quebradas of Valparaiso while urban units are constituted as a complex socio-spatial reality, and have a set of meanings, representations and social imaginaries associated with rural life.

To understand the logic of this type of appropriation of space in the quebradas (illegal footage of land) was used to its main actors, "its residents", who showed and revealed from their experiences, their expectations and their projects to come, this re-composition imaginary of rural life in the urban space.

KEYWORDS

rural life, quebradas, informality, imaginary

\section{Recomposition de la ruralité dans l'imaginaire urbain: l'exemple des quebradas de Valparaíso \\ RÉSUMÉ}

Cette recherche vise à découvrir et de révéler les processus socio spatiaux liés à la mise en place, la recomposition et la consolidation de la vie rurale dans l'habitat informel présent dans les quebradas de Valparaíso, en exposant les représentations sociales que ses habitants possèdent. Les quebradas de Valparaíso, en tant qu'unités urbaines sont constituées comme une réalité socio spatiale complexe, qui abrite un ensemble de significations, représentations et imaginaires sociaux liés à la vie rurale.

Pour comprendre la logique de ce type d'appropriation de l'espace dans les quebradas (prise illégales de terres) nous avons écouté ses acteurs principaux, "ses résidents" qui ont exposé et révéler par leurs expériences, leurs attentes et leurs projets à venir, cette recomposition imaginaire de la vie rurale dans l'espace urbain. MOTS CLÉS

ruralité, quebradas, informalité, imaginaire 
El fenómeno urbano de tomas de terrenos en las quebradas de Valparaíso está al origen del proceso de urbanización informal de la ciudad de Valparaíso, proceso evolutivo estrechamente ligado a la autoconstrucción como una forma de acceso a la casa y a la ciudad. Así mismo este proceso evolutivo está vinculado a una movilidad familiar influida por los sucesivos terremotos (Pino \& Ojeda, 2013) y por el proceso migratorio campo-ciudad desarrollado a principios del siglo XIX, cuando Valparaíso era el primer puerto de la costa del Pacífico sud (Pino, 2012).

Este proceso evolutivo de apropiación de las quebradas de Valparaíso implicó una compleja construcción de representaciones sociales que finalmente tienen una incidencia directa sobre el espacio construido, Denise Jodelet (1984) precisa que la noción de representación es una manera de interpretar y de pensar nuestra realidad cotidiana, es una forma de conocimiento social. Y correlativamente, es la actividad mental desplegada por lo individuos y los grupos para fijar sus posiciones con respecto a situaciones, eventos, objetos y de las comunicaciones que les conciernen (1984:3). Según Claude Flament, las representaciones sociales son un conjunto organizado de cogniciones relativas a un objeto, compartidas por los miembros de una población homogénea en relación a ese objeto (Negura, 1994:37-58), en este caso, cada quebrada en tanto que unidad urbana ${ }^{2}$ es definida e identificada por sus habitantes como un barrio $y / 0$ territorio que contiene y superpone una serie de representaciones, es por ello que uno de los enfoques de la presente investigación consistió en estudiar las representaciones sociales sobre el hábitat informal de dichas quebradas permitiéndonos reconocer los modos y procesos de constitución del pensamiento social, por medio del cual las personas construyeron y fueron construidas por su realidad social. Pero además, esto nos aproximó a la visión de mundo que estas personas o grupos tienen, pues el conocimiento del sentido común es el que la gente utiliza para actuar o tomar posición ante los distintos objetos sociales (Jodelet, 1984; Araya, 2002). En este caso este conocimiento empírico se ve reflejado no solamente en las representaciones sociales sino que también en el espacio construido como ejemplo tangible de aquellas representaciones (Abric, 1994).

Según Jodelet el concepto de representación social señala una forma de conocimiento especifico, un saber y un sentido común [...] señala una forma de pensamiento social [...] modalidades de pensamiento orientados a la comunicación, a lo comprehensivo y a la apropiación del entorno social, material e ideal (2011:367). Complementariamente Serge Moscovici (1986) define dos procesos que se refieren a la elaboración y al funcionamiento de una representación social: la objetivización y el anclaje.

En la objetivización las palabras sirven para objetivizar la representación, para construir lo real y encarnar el pensamiento. Es decir, hacer concreto lo abstracto. Así, la representación permite corresponder objetos con palabras y da cuerpo a esquemas conceptuales (Jodelet, 2011).

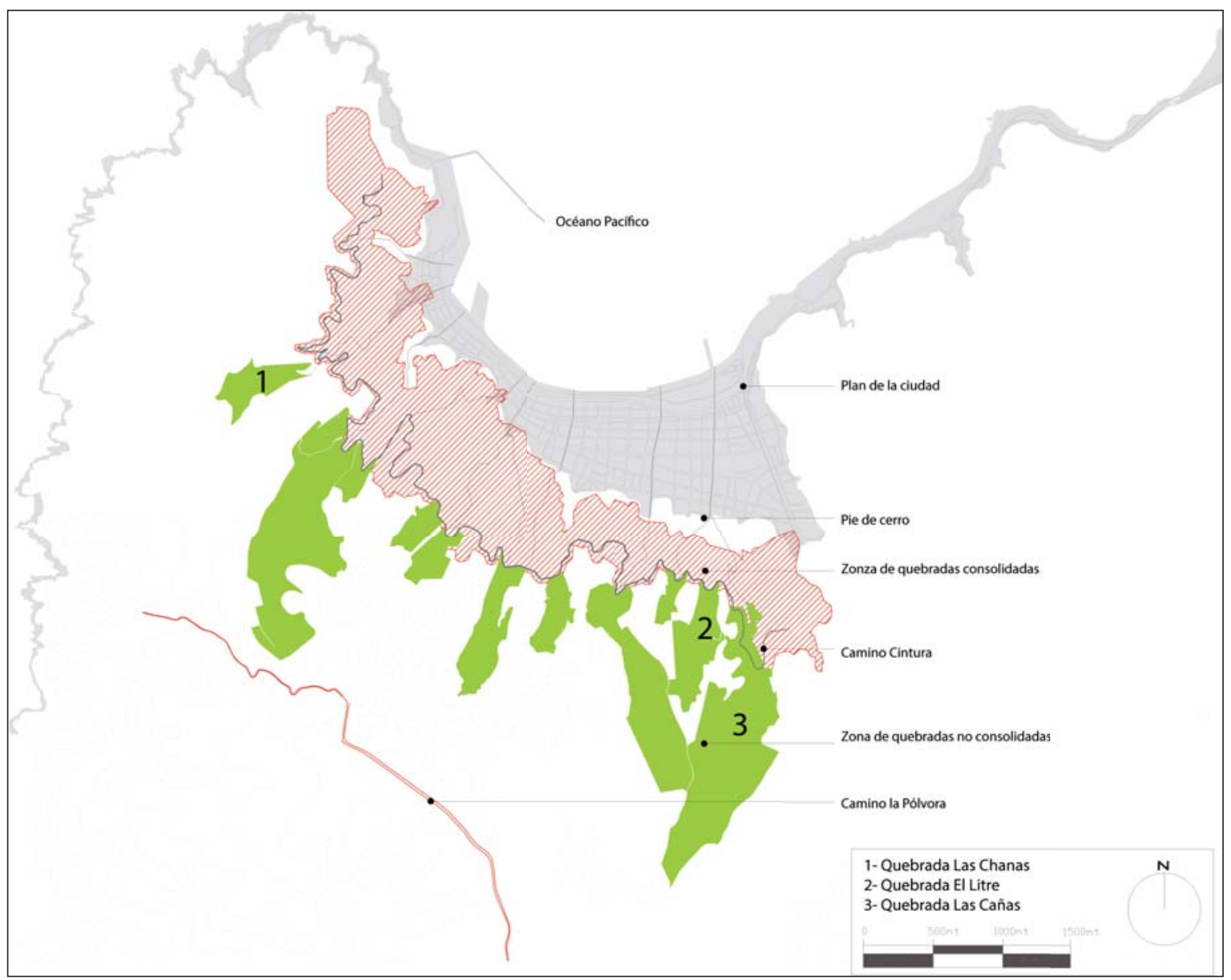

> Figura 1. Cartografía de Valparaíso que revela las 12 quebradas estudiadas. Fuente: autor.

50 > Revista Márgenes No 13 Vol. 10 > Diciembre 2013: 49-61 Facultad de Arquitectura > Universidad de Valparaíso
$>$ ISSN electrónico 0719-4436 $>$ ISSN impreso 0718-4034 


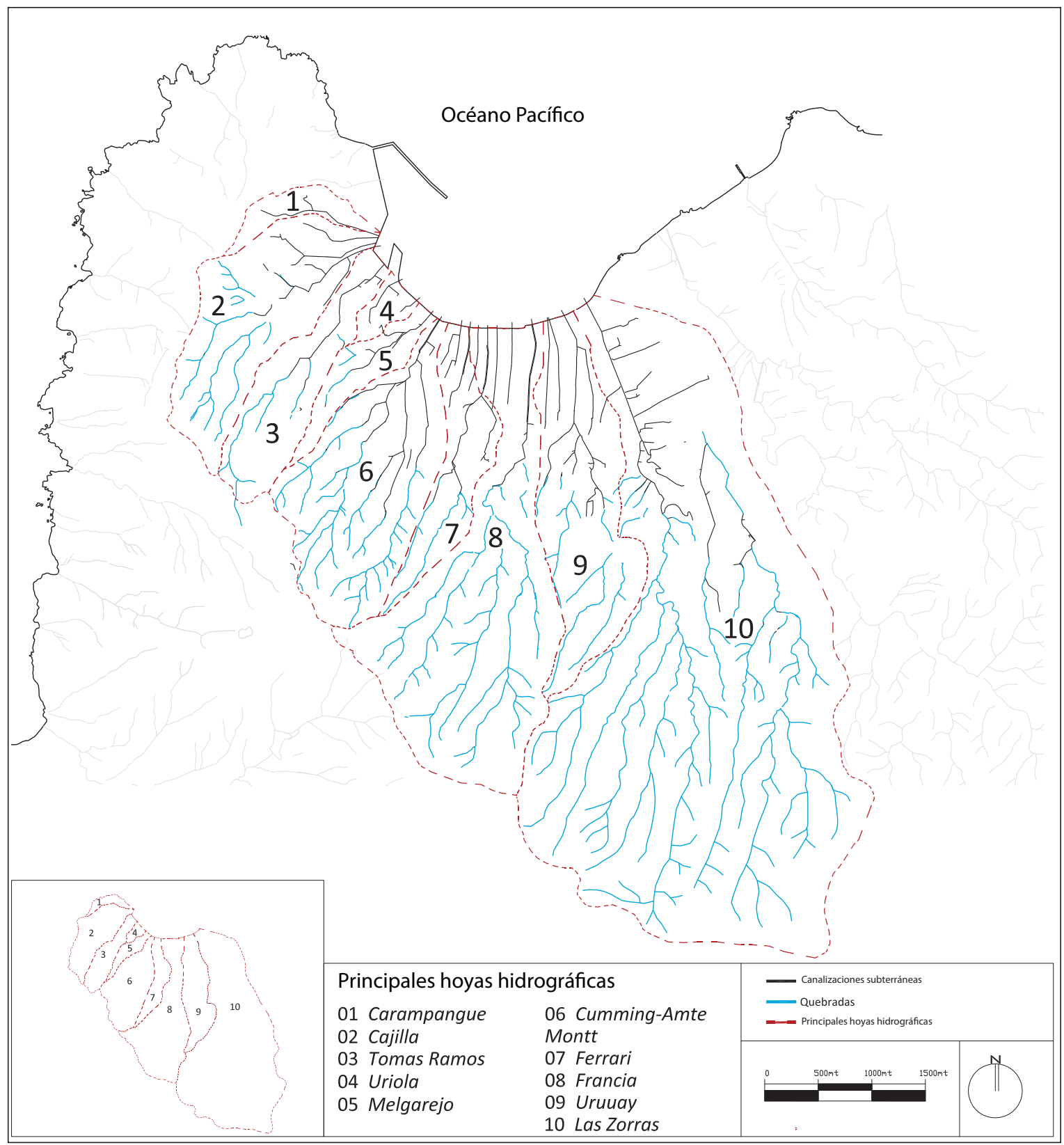

$>$ Figura 2. Cartografía oficial de la ciudad con las cuencas que la componen. Base cartográfica: Departamento de asistencia técnica de la I. Municipalidad de Valparaíso. Realización: autor.

El anclaje se refiere al enraizamiento social de la representación y de su objeto, Jodelet señala que la intervención de lo social se traduce en el significado y la utilidad que les son conferidos a la representación. El proceso de anclaje es dialéctico con el de objetivización y articula las tres funciones básicas de la representación:

a. función cognitiva de integración de la novedad

b. función de interpretación de la realidad

c. función de orientación de las conductas y relaciones sociales

De esta manera toda representación social se define por una parte por su contenido, es decir, el conocimiento e informaciones que vehicula y por otra parte es la representación de un sujeto (individuo grupo, familia, clase, etc.), es decir, toda representación social es una representación de algo o de alguien (Jodelet, 2011:368).

Re-composición de la ruralidad en el imaginario urbano: el caso de las quebradas de Valparaíso > Andrea Pino Vásquez
En este caso hemos analizado la casa o el hogar como el "algo", el cual es el reflejo de la construcción de la representación que cada habitante posee, condensado y asociado a una imagen mental. Los relatos de vida vehiculan una serie de representaciones y por consecuencia múltiples imágenes que se consolidan a través del tiempo. Se transmiten mediante la oralidad, y en este caso, por medio de palabras y adjetivos específicos, que cualifican y describen el lugar donde habitan.

\section{METODOLOGÍA}

Para comprender y dar cuenta de las significaciones y representaciones que poseen los habitantes de las quebradas sobre los procesos y los mecanismos sociales insertos en la construcción social de estos territorios, se utilizó como herramienta investigativa el método de los "relatos de vida", metodología que se inscribe dentro de la perspectiva etno-sociológica. Perspectiva definida por
Revista Márgenes № 13 Vol. 10 > Diciembre $2013>51$ Facultad de Arquitectura > Universidad de Valparaíso 
Daniel Bertaux como: un tipo de investigación empírica fundada en la entrevista de terreno y en los estudios de caso, que se inspira de la tradición etnográfica por sus técnicas de observación, pero que construye sus objetos por referencia a problemáticas sociológicas[...] una investigación que no se inscribe en el mismo espacio epistemológico que aquel que se elabora a partir de otra forma de entrevista, la entrevista por cuestionarios sobre una muestra representativa (2010:15).

El relato de vida es un tipo de entrevista no-directiva, que se caracteriza por el hecho que el entrevistador (en este caso quien suscribe) plantea al interrogado una sola pregunta directa, Ilamada "consigna inaugural". Para que las sucesivas intervenciones que haga el entrevistador solo sean pequeñas injerencias con el objetivo de relanzar el discurso y motivar a la persona entrevistada a profundizar y a enriquecer su relato. Bertaux propone que hay relato de vida en la medida que un sujeto cuenta a un otro sujeto, investigador o no, un episodio cualquiera de su experiencia vivida (2010:35). Este método nace de un tipo particular de entrevista.

Por lo tanto, en el relato de la vida en tanto que narrativa, el sujeto (en nuestro caso, los habitantes de las quebradas de Valparaíso), cuenta y desarrolla su discurso en relación a una consigna inaugural. En nuestro caso la consigna o la única pregunta planteada a los entrevistados fue: ¿Podría usted contarme su historia, cómo llegaron a vivir a la quebrada y cómo construyó su casa?

La consigna inaugural tiene por objetivo enmarcar la realidad social estudiada, tratando de asir una parte de la experiencia de los habitantes de las quebradas, específicamente las experiencias relacionadas con la construcción y consolidación de sus hábitats. De esta manera la consigna inaugural actúa como el "filtro" a través del cual puede seleccionar inconscientemente en el universo semántico, la suma interna de sus experiencias, y que sería capaz de cumplir con las expectativas del investigador (Bertaux, 2010:48). Así, el relato de vida es construido por el habitante y aprehendido por el investigador con una intención de conocimiento específico.

De esta manera, el estudio de la realidad social de las quebradas de Valparaíso, mediante el método del relato de vida resultó ser muy eficaz, ya que hemos sido capaces de captar y comprender una variedad de situaciones, acontecimientos, acciones y proyectos, desde la experiencia de sus habitantes. Esto nos permitió comprender la lógica interna de cómo fueron construidos social y espacialmente estos territorios en la ciudad, tanto a nivel familiar como comunitario.

\section{Selección de los informantes}

En la investigación centrada en los relatos de vida, Esther Wiesenfeld señala que la selección de los informantes es intencional, es decir, los actores se escogen con algún propósito definido, según la concepción que se tenga del problema o de su fundamentación. Es primaria, ya que permite detectar informantes que tienen el conocimiento y la experiencia requeridos para la investigación (2001:152).

Esta aproximación inicial nos permitió identificar de forma previa a los habitantes que presentaban ciertas características de interés en relación al objeto de la investigación, y que nos podrían entregar la información necesaria para comprender el proceso y las causas que llevaron a la ocupación de estas quebradas.

Esto nos permitió refinar la selección de informantes a medida que avanzaba la investigación. A este respecto, Wiesenfeld, señala que la selección de informantes permite un mayor alcance y rango de

52 > Revista Márgenes № 13 Vol. 10 > Diciembre 2013: 49-61 Facultad de Arquitectura > Universidad de Valparaíso los datos, aumenta la probabilidad de que toda la gama de múltiples realidades sean develadas, maximiza la incorporación de condiciones y valores locales que eventualmente podrían transferirse a otros contextos (2001:152). En nuestro caso, el objetivo era recoger el máximo de puntos de vista posible para obtener una diversidad de posiciones y opiniones. Desde estos diferentes puntos de vista, hemos reconocido las repeticiones y contradicciones en los discursos recogidos: por ejemplo, personas que han llegado a la quebrada, pero que quieren salir de ella y otros, que por el contrario no se imaginan vivir en otro lugar.

Ante esta realidad, establecimos cuatro categorías de informantes, que desde sus propias opiniones fueron alimentados y dieron forma a la historia común de cada una de estas quebradas. Los grupos de informantes son:

Los habitantes fundadores (HF)

Este grupo está conformado por las primeras familias que llegaron a las quebradas, y que han sido testigos de los primeros cambios, tanto espaciales como sociales. Estos informantes han sido testigo del poblamiento progresivo de la quebrada. Por lo tanto son informantes que nos trajeron datos claves en lo que respecta a la línea de tiempo de ocupación de las quebradas.

Los habitantes de conjuntos residenciales familiares (HCRF)

En segundo lugar, reconocimos una forma particular de apropiación y gestión del espacio, mediante "Conjuntos Residenciales Familiares" (CRF) (Pino, 2012), entendido en el sentido propuesto por Michel Agier (2009) que se refiere a cómo las familias se recomponen en el espacio urbano y se mantienen conectados, teniendo varias ramificaciones residenciales (Agier, 2009).

Estos informantes fueron elementos clave para la comprensión de los mecanismos de apropiación y construcción del espacio construido, revelando una organización social que resulta de una estructura de familias extendidas ${ }^{3}$ que revela un estilo de vida reflejada físicamente en esta particular tipología del hábitat de las quebradas (CRF). Con el HCRF, la diversidad de las posturas se define por distintas generaciones de entrevistados, estableciendo un arco temporal que puede ir hasta cinco generaciones sucesivas.

Los habitantes dirigentes sociales (HD)

En tercer lugar, buscamos personas que formaran parte de una organización social y con un rol importante en la comunidad, como por ejemplo los dirigentes o representantes sociales, los miembros de las juntas de vecinos o los coordinadores municipales. La elección de estos informantes apuntó a develar si existía o no un tipo de organización social en el interior de las quebradas. Esto nos permitió conocer el nivel de participación de los habitantes sobre proyectos y objetivos en común. La incorporación del HD nos aportó el marco administrativo y/u organizacional, proceso ausente en el origen de una toma en una quebrada, donde su forma de apropiación es de carácter familiar informal y no necesariamente colectiva. La variedad de posiciones encontradas entre los $\mathrm{HD}$ obedece a la función que desarrollan en la actualidad. Existen informantes que participan activamente en la función administrativa y otros que son más bien disidentes, es decir, que han abandonado o renunciado a sus cargos ${ }^{4}$.

\section{Los habitantes nuevos (HN)}

En cuarto lugar, hemos buscado los recién llegados. En promedio, las quebradas tienen una antigüedad de ocupación del orden de 30 años. La mayoría de las familias se conocen desde hace años y han 
construido una historia en común. Además la movilidad residencial es baja; es decir muy pocas familias de las quebradas se van a vivir en otro lugar. Frente a esta aparente cohesión de grupo, nos pareció importante integrar a la minoría de los recién llegados, teniendo en cuenta que podrían aportar un punto de vista opuesto al de los habitantes fundadores, quienes están emocionalmente vinculados a estos territorios. Por lo tanto, el objetivo fue revelar si los nuevos habitantes poseían o no las mismas representaciones sociales que los habitantes fundadores. También esta visión nos permitió identificar opiniones negativas sobre el hecho de vivir en una quebrada, lo que sin lugar a dudas es producto de una visión, que al ser desprovista del peso de la historia, tiende a ser más objetiva.

\section{ANÁLISIS TEMÁTICO}

El análisis del contenido de las entrevistas se realizó mediante un análisis temático, el objetivo de esta forma de análisis como método de análisis de contenido, es de identificar las unidades semánticas que constituyen el universo del enunciado. En estas condiciones, se trata de producir una reformulación del contenido del enunciado bajo una forma condensada y formal. Para realizar esta tarea, se procede en dos etapas; la identificación de las ideas significativas y su categorización. Así, mediante la categorización, obtenemos una modalidad práctica para el tratamiento de la información que tenemos a granel (Negura, 2006).

\section{El hábitat informal en Valparaíso / tres escalas de intervención}

Dos de las temáticas más recurrente que aparecieron en las entrevistas fueron el "Sueño de la casa propia" y la noción multi-escalar de intervención del hábitat informal.

La vivienda en Chile representa un bien preciado, es considerado el patrimonio familiar, la casa en sí, es desde donde podemos desarrollarnos, representa quienes somos, representa el esfuerzo, y los sueños de cada familia. Es por ello, que el fenómeno de las tomas de terrenos no debería sorprendernos si comprendemos que todas las personas tienen derecho "al sueño de la casa propia".

Sin embargo, en Chile la vivienda de carácter formal, se volvió inalcanzable para la clase social más desfavorecida, la cual durante años ha tenido que recurrir a nuevas formas de acceso a la vivienda y a la ciudad.

Este acceso a la ciudad, nace de la necesidad de beneficiarse de todos los servicios que la ciudad ofrece, cuyo principal atrayente es la concentración de puestos de trabajos, que buscan aquellos que dejaron el mundo rural en pos de nuevas opciones de vida.

De esta manera, aparecen territorios informales, por donde la ciudad crece y se expande, al interior de ellas o en sus periferias, los cuales se generan mediante una inclusión de suelos rurales a suelo urbano, para poder hacer frente ha dicho crecimiento. Joan Busquets señala que los asentamientos precarios pueden entenderse como una forma de crecimiento que se apoya en la transformación de suelo rústico a "urbano" a través de la simple definición de las parcelas que, a su vez, son el soporte de la construcción de correas sin la previsión de ningún tipo de urbanización (1999:78).

Así, lo informal en relación al hábitat en las quebradas, se expresa materialmente en tres escalas complementarias, las cuales están en constante mutación.

- La primera es una escala territorial, que debiera estar casi encomendada al antiguo augur, que es la elección de un lugar propicio para la toma. Este primer acto, se constituye como la toma de posesión de un lugar. Sea por una colectividad, por un pequeño grupo o de forma individual. Y que habitualmente se genera en terrenos o zonas de la ciudad poco valoradas económicamente, en zonas de riesgo o en zonas despreciadas. En esta escala territorial, se lotean los terrenos, definiendo así los sitios, donde hay un primer intento de distribución y trazado del espacio público, definiendo vías de acceso y espacios de recreación expresados básicamente como "desplayos" para jugar fútbol. Lo cual, implica una auto-organización de la parte del grupo o familia.

- La segunda es una escala familiar o personal, que se constituye con la autoconstrucción de la casa, sea una pieza, una mediaagua, un rancho. Acto no planificado, realizado sin permisos, ni con las regulaciones técnicas que establece la Ley. Si no, que se constituye en la inmediatez con el medio natural, el paisaje y con los medios económicos y materiales disponibles.

- La tercera es una escala de barrio, que se constituye con la autourbanización informal del espacio de carácter público, en pos de una mejora del entorno de la vivienda. Esto puede implicar la instalación de redes básicas de suministro de agua y de electricidad, así como también el alcantarillado. Como también el mejoramiento o creación de equipamientos de uso público.

Consideramos que esta es la tercera y la última escala de intervención en Valparaíso, porque esta comienza a gestarse cuando las dos escalas previas ya están aseguradas, además, porque todos los terrenos ocupados por una toma, no estaban previamente urbanizados. A excepción de los terrenos otorgados en el gobierno de Eduardo Frei Montalva, con el programa "Operación sitio", que preveía con antelación la urbanización de los sitios a ocupar.

Las quebradas de Valparaíso son por lo tanto territorios multiescalares en constaste configuración que obedecen a sus propias lógicas de crecimiento y consolidación y que hoy día presentan un tejido urbano propio y de desarrollo orgánico.

\section{La quebrada y la casa}

En los tres territorios expuestos, exploramos tres escalas de apropiación sustentada por las representaciones colectivas que tienen los habitantes de las quebradas con respecto a su posición, relación y participación con el mundo interno y externo de estas. El objetivo de este artículo es profundizar la segunda apropiación: la casa y su imaginario rural.

La "casa" como un concepto general, se entiende como un espacio físico que da cobijo a una familia y como un espacio simbólico que da lugar a la socialización humana. El filósofo Gastón Bachelard define la casa como nuestro rincón del mundo. Es -lo hemos dicho reiteradamente- nuestro primer universo. Es realmente un cosmos (Bachelard, 2011:24).

Paralelamente, más allá de presentarse como una construcción física, la casa es una construcción social construida bajo los parámetros de las normas sociales (Di Méo, 1998:97), esto es un micro territorio apropiado que territorializa las prácticas socio-espaciales de la vida cotidiana, porque La casa habitada no es una caja inerte. El espacio habitado trasciende el espacio geométrico (Bachelard, 2011:58).

La casa no es sólo el resultado de un entorno físico de fuerzas externas que afectan a la vivienda, es principalmente el resultado de los factores socioculturales que definen su forma. Amos Rapoport, en su libro para una Antropología de la casa (1972) refiriéndose a la arquitectura popular, indica que el concepto de "estilo de vida" utilizado por Max Sorre ilustra esta idea, porque incluye todos los aspectos 
culturales, materiales, espirituales y sociales que afectan a la forma. Podemos afirmar que casa y asentamientos son la expresión material del estilo de vida, y este es su carácter simbólico (Rapoport, 1972:66).

Es mi casa, donde me siento bien, este es mi mundo, este es el lugar donde estoy en paz. Mi casa es diferente a las demás, con mis plantas, incluso si es fea, las plantas le dan una vida (HF, 54 años, quebrada Las Cañas).

Esta forma de apropiación de escala local se realiza desde la visiones de mundo, ideas, representaciones, imágenes, recuerdos, que los habitantes poseían a su llegada a la quebrada. Al mismo tiempo, esta apropiación posee un recorrido progresivo y colectivo en la medida que las familias interactúan unas con otras y se apropian de ideas, imágenes y visiones del mundo de los otros habitantes, Wiesenfeld señala que la vivienda auto-construida inspira un conjunto de sentimientos entre los que se mencionan quererla, recordarla, sentirla, apreciarla, sentirse contento, orgullo, feliz, realizado e ilusionado con ella. Este tipo de sentimientos corresponde con lo que se ha denominado el apego residencial o vínculo afectivo profundo que ata a la gente a los lugares y les provee un anclaje importante para la definición de su identidad personal y grupal. Impele, además, a la realización de un conjunto de prácticas de apropiación orientadas a preservar el lugar, a fomentar las relaciones vecinales y a promover la permanencia en él (Wiesenfeld, 2001:299). Por lo tanto, la construcción de la casa no es sólo un reflejo de las representaciones particulares de cada familia, sino también es el producto de las representaciones movilizadas por el grupo. A este propósito Olivier D'Hont señala que de la vivienda, apropiada por varios, es a menudo en su morfología la representación simbólica del cosmos, un cuerpo mítico y por su organización, la transcripción del espacio doméstico de un orden social (2005:169).

Así este espacio simbólico vehicula representaciones, significados, identificaciones alrededor de sí mismo, que afectan su forma construida. Así entendemos el concepto de casa en una doble relación, tangibles e intangibles, como una expresión que engloba los aspectos sociales, materiales y estéticos al origen mismo de la significación. En este sentido Rapoport señala que Es el compartir una misma visión de mundo, una imagen y sistemas de valores específicos que hace posible el proceso de construcción [...] y que el objetivo de la composición urbana sería las relaciones armoniosas entre los edificios (Rapoport, 1972:66), y agrega que en la construcción del hábitat se expresa el entorno ideal de un pueblo.

En este contexto, consideramos que los habitantes de las quebradas poseen una apreciación positiva de la casa como un espacio apropiado y autoconstruido, que establece un vínculo territorial, expresando un apego entre la casa y lo que representa. Quezada concluye que esto se debe a que existe el sentimiento de aceptación y de afección (topofilia), pero también, implica un sentimiento de rechazo o disgusto de ello, elementos que afectan la conformación de la identidad socio-territorial (2007:13).

Es por ello que los habitantes atribuyen a su hogar una doble valorización, una intangible (emocional) y otra tangible (estética), directamente relacionada con el esfuerzo realizado para su construcción y con la transmisión de este patrimonio. Por otro lado, estos constructores autodidactas saben (en tiempo y espacio) adaptar sus construcciones con una notable sabiduría en relación al medio ambiente (Berenstein, 2001).

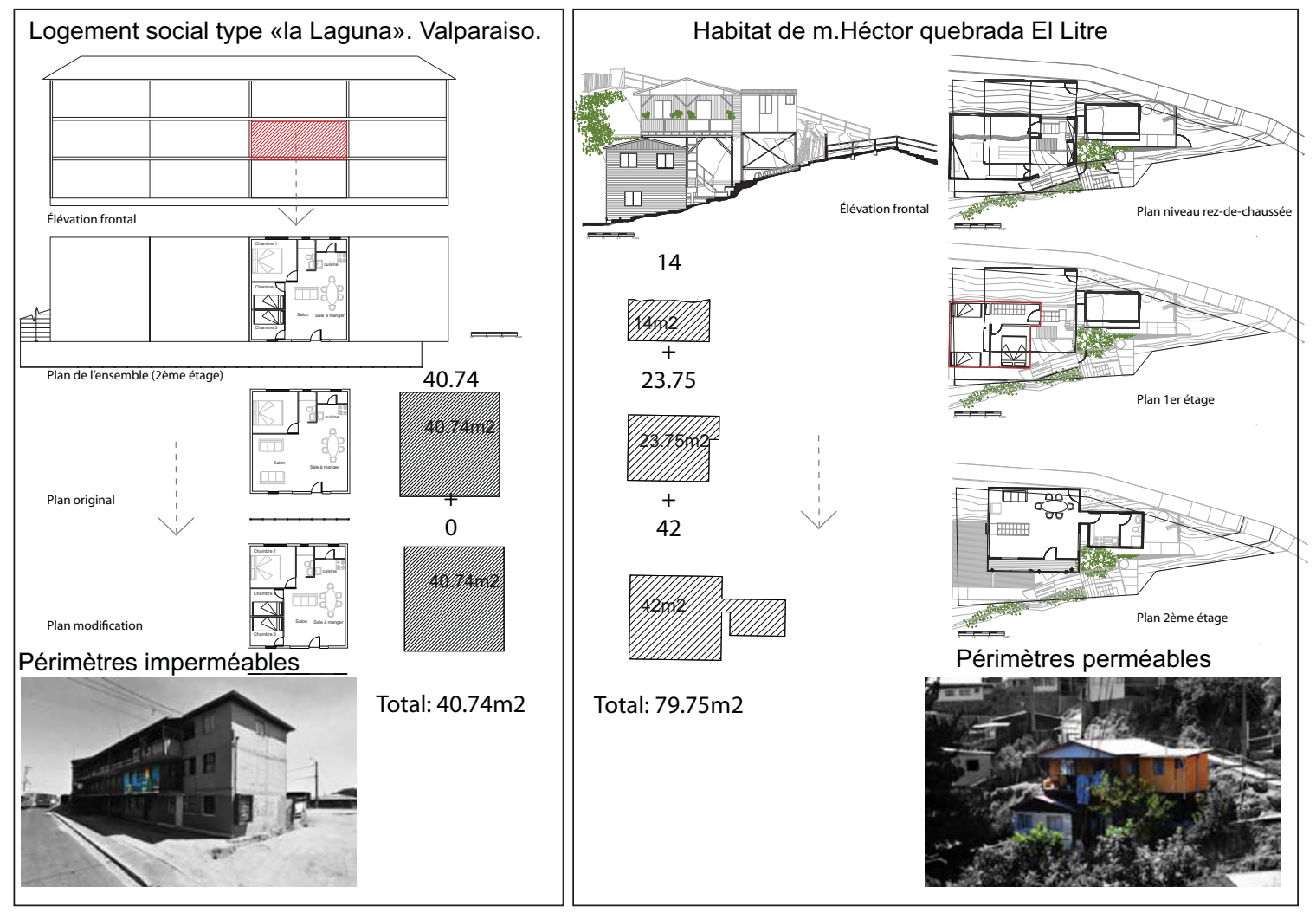

> Figura 3. Lámina que muestra la evolución de un hábitat autoconstruido en las quebradas de Valparaíso comparada con las posibilidades de crecimiento de una vivienda social en bloque; la vivienda autoconstruida posee una flexibilidad espacial debido a sus perímetros permeables, lo cual contrasta con los perímetros impermeables de las viviendas sociales en bloque. Fuente: Autor.

54 > Revista Márgenes N 13 Vol. 10 > Diciembre 2013: 49-61 Facultad de Arquitectura > Universidad de Valparaíso 
En relación al valor material y social de la vivienda auto-construida, John Turner, en su libro Freedom to build (1972) identifica tres aspectos de los procesos de autoconstrucción de vivienda, aspectos conocidos como "las tres leyes de Turner". La segunda de estas "leyes" se refiere a la satisfacción cualitativa que proporciona la vivienda al usuario, más allá de su calidad material, lo importante es el efecto de la casa sobre los habitantes y no lo que "es" en términos materiales. La tercera "ley" se refiere al grado de tolerancia frente a las imperfecciones constructivas y espaciales de la auto-construcción: para los auto-constructores es más fácil encontrar errores en un edificio normado (por ejemplo una vivienda de interés social), que en una construcción hecha por el mismo. Resulta que las personas son más proclives a hacer concesiones a sus propios errores que a los de los demás, ya que la casa de autoconstruida es el resultado de un continuo "hacer" $y$ "rehacer" y por lo mismo de ensayo y error.

En estas acciones sucesivas de hacer y rehacer se encuentra una de las principales características de la casa de la quebrada. Es la casa como un espacio físico resultado de sucesivas modificaciones realizadas desde una lógica de crecimiento fragmentario.

Por lo tanto es una construcción progresiva, gradual y que se materializa progresivamente a partir de fragmentos asociadas a una idea o proyecto global. La casa, como un concepto genérico, es por lo tanto, un proyecto para el futuro que, suele comenzar a partir de dos unidades primitivas: la "mediagua» y/o la habitación.

Desde este punto de vista la casa de la quebrada, está en constante proyección, evoluciona a partir de los deseos y sueños de las familias. Respecto a esto Bachelard indica que la casa cobija el ensueño, la casa protege al soñador, la casa nos permite so- ñar en paz (2011:26) y que a veces la casa crece, se extiende. Se necesita una mayor elasticidad de ensueño, ensoñación menos definida, para poder habitarla (2011:61). Esta "ensoñación menos definida" define de manera certera el proyecto arquitectónico de una casa de la quebrada, un proyecto que puede entenderse como un palimpsesto de imaginarios que será diseñado y rediseñado, hecho y rehecho desde los aspectos socio-culturales y materiales sometidos a la apropiación del espacio de las quebradas.

El reinicio de la casa como una "ensoñación menos definida" es continua y no visualiza su finalización. Es producida por el carácter precario y/o perentorio de los materiales utilizados, todos los cuales tienen una vida diferente, algunos se desgastarán antes que otros, y de este modo se propicia el inicio, re-inicio y superposición de los procesos de hacer y rehacer la casa.

Así, cuando se analizan los relatos de los habitantes, se subentiende una proyección de una casa a medio terminar (según nuestra percepción); en cambio los habitantes hablan de una casa que no está totalmente acabada, puesto que la presentan como un proyecto de casa o una idealización de esta, como por ejemplo "la casa quinta" o la "casa chalet", por lo tanto, hablan al mismo tiempo de su casa actual y de su casa idealizada, y que tal vez algún día se acabe.

\section{Representaciones sociales de los habitantes de las quebradas en sus hogares}

A continuación presentaremos las diversas representaciones que poseen los habitantes de las quebradas con respecto a sus casas. Los relatos de los habitantes cargan múltiples representaciones y, por tanto, múltiples sedimentaciones de imágenes, consolidados a lo largo del tiempo. Estas se transmiten a través de la tradición

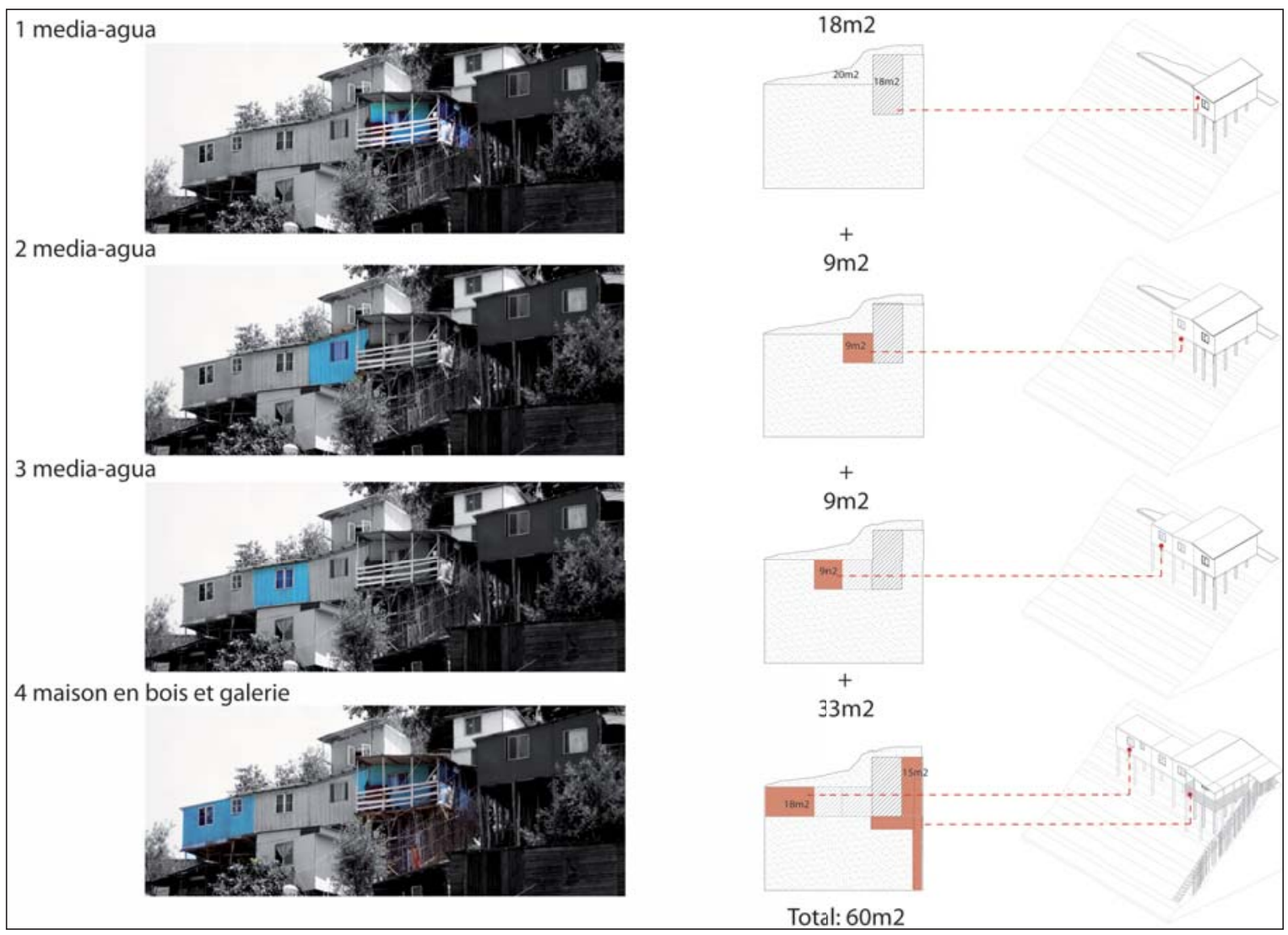

> Figura 4. Evolución de una vivienda autoconstruida en la quebrada Las Cañas. Fuente: Autor. 
oral, con los nombres y adjetivos específicos que describen y cualifican el lugar donde viven.

Cada habitante $\mathrm{y} / \mathrm{o}$ familia, a partir de su experiencia personal y colectiva, retraduce la representación que posee de su casa a una imagen particular, que figura aquella representación y le otorga un significado. Es decir, cada habitante posee su propia imagen mental, de que lo que es una casa, y de lo que es su casa y ésta a la vez por ser particular posee una identidad, que está definida por un sinfín de elementos que la hacen diferenciable de las otras. De esta manera las palabras que definen y caracterizan las viviendas autoconstruidas en las quebradas, nos revelan las diferentes concepciones de mundo que poseen sus habitantes y cómo éstas se retraducen en un símbolo de identidad social y constructiva. La casa como forma construida expresa la identidad de sus moradores y su agenciamiento con el medio natural, así como la figuración que ellos construyen con respecto a esa forma.

Las representaciones sociales construidas por los habitantes alrededor de su casa son formas de interpretar y pensar una realidad cotidiana de vivir en una quebrada, donde las formas construidas son el espejo, una forma transmisible a partir de la palabra. La casa como expresión concepción del mundo (Rapoport, 1972) tiene múltiples representaciones (como diversas concepciones de mundo) vehiculando más de una imagen. En las quebradas, cada persona o cada familia, desde su experiencia personal y colectiva, reinterpreta la representación que posee de su hogar a una representación particular e intransferible, representación que le da un significado único. De este modo las palabras que definen y caracterizan las viviendas auto-construidas en las quebradas, nos revelan las diferentes concepciones de mundo que tienen sus habitantes y cómo éstos son un símbolo de su identidad social y constructiva.

Sin embargo, antes de desarrollar las representaciones que seleccionamos (la representación rural, la representación de emergencia, y la representación formal y material), tenemos que definir cada una de las significaciones usadas por los habitantes para referirse a su casa.

\section{Tres representaciones de la casa en la quebrada: rural, emergencia y material}

Para la mayoría de nosotros, una casa es un lugar compuesto por diferentes espacios, habitado por una persona y/o una familia donde cada uno de estos espacios posee un carácter muy específico, en relación a la función que acogen.

Pero a diferencia de esta idea de casa genérica, para las familias que viven en las quebradas, esta es una idea o una noción extranjera. La representación de una casa acabada, terminada, consumada, perfecta, con espacios diferenciados, es una idea o representación que sólo ocurre en los sueños de las familias que habitan en una quebrada. Es una representación que toma todo su significado en un futuro que puede ser distante o próximo, en función de las posibilidades económicas de cada familia y que seguramente se materializará poco a poco. Por lo tanto, las representaciones que tienen los habitantes de las quebradas en relación a la casa, son las de una casa inacabada, incompleta y en base a una construcción evolutiva, fragmentaria, pero es también una casa idealizada, que a veces se dibuja desde los ideales habitables reconocidos para ser digna de ese nombre y para identificarse con los demás.

Sin embargo, antes de la identificación y definición de cada acepción utilizada por los habitantes de las quebradas para definir sus hogares, debemos señalar que la palabra más usada es la "casi- ta $w^{5}$, noción que establece una doble acepción, una formal y otra emocional que implica un apego íntimo a la vivienda.

De la misma manera, cada palabra utilizada por los habitantes de las quebradas para definir su casa está amañado el sufijo ita o ito, lo que define las características formales de la casa y paralelamente el apego al lugar.

Las representaciones en tanto que imágenes se explicitan mediante el lenguaje, en este caso precisamente con las palabras que sus moradores utilizan al referirse a sus casas. Un claro ejemplo de la complejidad de los diferentes sinónimos que posee el concepto de casa en el Chile es la inclusión de éstos en las encuestas del censo nacional. Esto permite definir de manera más precisa las diferencias formales y constructivas de la vivienda en Chile y su influencia directa en la caracterización socio-económica. De esta manera, encontramos en el glosario del censo nacional los siguientes sinónimos: mejora, mediagua, pieza en casa antigua o conventillo, rancho, choza, ruca, vivienda, vivienda colectiva pública y privada.

En el caso de las quebradas de Valparaíso, en las variadas representaciones que los habitantes poseen de sus viviendas, hemos reconocido tres grupos de representaciones, cada una de los cuales está ligada a más de una imagen y además vehiculan un significado social y un significado constructivo.

Estos tres grupos reconocidos son:

1. representación de la casa en relación a una imagen campestre en la ciudad

2. representación de la casa en relación a una imagen de emergencia 3. representación de la casa en relación a las características o identidad constructivas.

A continuación presentamos un resumen de las acepciones y significados de los términos empleados en los tres grupos reconocidos.

1. Imagen campestre en la ciudad

En este grupo encontramos las siguientes acepciones: rancho, ranchito, choza, chocita, casa quinta, casita quinta.

a. Rancho: Lugar fuera de poblado, donde se albergan diversas familias o personas. Rancho de gitanos, de pastores. 0 granja donde se crían caballos y otros cuadrúpedos. En Chile se utiliza el término rancho para definir los patios donde son criados los puercos, los caballos, las vacas, los conejos, las gallinas, etc... ${ }^{6}$

b. Ranchito: Diminutivo de rancho que denota cariño y pequeñez. c. Choza: Construcción rústica pequeña y tosca, de materiales pobres, generalmente palos entretejidos con cañas, y cubierta de ramas, destinada a refugio o vivienda de pastores, pescadores y gente humilde. 0 casa pobre con techumbre de ramas o paja, fuera de poblado.

d. Chocita: Diminutivo de Choza. El glosario del censo nacional agrupa el Rancho y la Choza bajo la misma definición, y señala que el rancho o choza con una construcción típicamente rural con materiales ligeros (barro, totora, pirca, etc.).

e. Quinta o casa quinta: Casa de recreo en el campo, cuyo arriendo solía ser la quinta parte de la recolección de los frutos. 0 casa con antejardín, o rodeada de jardines. 0 Huerta de extensión variable dedicada al cultivo de hortalizas para el consumo familiar o con fines comerciales.

f. Casita quinta: Diminutivo de Casa quinta.

2. Imagen de emergencia

En este grupo encontramos las siguientes acepciones: pieza, piececita, cuarto, cuartito, mediagua, mediagüita.
56 > Revista Márgenes № 13 Vol. 10 > Diciembre 2013: 49-61 Facultad de Arquitectura > Universidad de Valparaíso
$>$ ISSN electrónico 0719-4436 > ISSN impreso 0718-4034 
a. Pieza: Significa literalmente un cuarto o una pieza que forma parte de un conjunto, en Chile suele llamarse pieza a los dormitorios. b. Piececita: Diminutivo de pieza.

c. Cuarto: Sinónimo de pieza.

d. Cuartito: Diminutivo de cuarto.

e. Mediagua: Una mediagua es una construcción con un techo inclinado y de una sola pendiente (RAE, 2009). Según el censo nacional del año 2002, una mediagua es una construcción de material ligero de naturaleza semi-transparente. Generalmente están compuestas de una o dos piezas, poseen un suelo de tierra o en madera, y los baños suelen estar en el exterior de la vivienda. f. Mediagüita: Diminutivo de mediagua.

\section{Características o identidad constructivas}

En este grupo encontramos las siguientes acepciones: chalé, chalecito.

a. Chalé: Proviene de la palabra francesa chalet, y hace referencia a una cabaña, o una habitación de los Alpes, principalmente en madera con cubiertas muy grandes. Según el CNTRL ${ }^{7}$ es una Habitación de los Alpes, construida en madera, generalmente ornamentada con balcones y cobijado por un gran techo de doble pendiente. En Chile este término se utiliza para definir una casa que tienen balcones, que es estéticamente bella y agradable para vivir.

b. Chalecito: Diminutivo de chalet.

\section{Representación de la casa en relación a una imagen campestre} en la ciudad

Antes eran puras rancherías (HD, mujer, 57 años, quebrada Las Cañas).

La migración campo-ciudad, desde la segunda mitad del siglo XIX, implicó un traslado y una superposición de culturas, desde lo rural a lo urbano. Reproduciendo de esta forma un modo de habitar campestre en la ciudad.

Este grupo de representaciones relacionadas con el fenómeno del éxodo rural, que implicó una recomposición de la forma de hábitat y de los refugios como los son "ranchos", "quintas" y "chozas". Cada una de estas apelaciones representa una forma y un programa de arquitectura preciso, donde la "choza" es el hábitat menos desarrollado y la casa quinta la más avanzada. Los habitantes que usan este tipo de representación han vivido en el campo o han vivido en casas muy precarias similares a ranchos o chozas. Este grupo de apelativos conforma una recomposición de la vivienda rural en el imaginario urbano, reconstruido y reinterpretado en la ciudad.

A partir de ellos podemos concluir que las representaciones rurales que poseen los habitantes están íntimamente asociadas a sus trayectorias residenciales, puesto que las familias provenientes del mundo rural que migraron en las quebradas, encontraron en estos territorios ciertos elementos y aspectos que les recordaron su lugar de proveniencia, y de este modo transpusieron de forma natural las representaciones de su antigua vivienda rural a la nueva construcción que establecieron en una quebrada de Valparaíso.

La representación que se construye en torno a la vivienda, tiene que ver con la superposición de la experiencia anterior, que posee la familia o en este caso quien relata. Al respecto Alicia Lindón señala que Por esta condición que asocia la casa a su habitante y a su existencia, es que la casa también lleva consigo una memoria. Pero es una memoria compleja, no es sólo de lo vivido allí sino también de lo que se ha vivido en otras casas pero que entra en el juego de las analogías y contrastes permanentes. Al mismo tiempo, la protección de la casa hace que en ella también se incluya lo que su habitante proyecta en un horizonte futuro, y no solo su pasado y presente (Lindón, 2005:7).

Por ejemplo en el relato una señora de la quebrada El Litre (HF, mujer 78 años), quien llegó a la quebrada en 1952, en busca de trabajo, desde Santa Juana, una comuna de la VIII región al sur de Chile, que a la época era un pueblito rural. En este contexto la imagen que la señora (HF, mujer 78 años) posee de su vivienda es una imagen de la memoria de su lugar de origen, donde existían grandes latifundios donde sus dueños los arrendaban a sus trabajadores por quintas, para ser cultivadas y con ello los trabajadores podían pagar el arriendo.

Yo que vivo acá señorita del año 52, así como más de 40 y tantos años, entonces vivíamos en una "chosita". [...] después yo me preocupe de plantar arbolitos, porque por aquí no hay ninguna otra casita que tenga "una casita quinta", yo iba plantando siempre de a poquito arbolitos, nacía un hijo y yo le plantaba un árbol, nacía un nieto y yo plantaba otro, al nacimiento de cada hijo y de cada nieto, entonces todos esos arbolitos, ahora me dan su fruto, la tierra que tengo ahí yo siembro me sirve para plantar papitas, porotos y así yo voy sacando las cositas que necesito (HF, mujer 78 años, quebrada El Litre).

Un lugar puede causar la reminiscencia de otro lugar, porque la gente moviliza sus prácticas en relación con sus propias experiencias, la señora (HF, mujer 78 años) reprodujo el estilo de vida de una pequeña casa quinta campestre en su casa actual, a pesar de que su calidad constructiva y los materiales difieren de una casa quinta convencional. Esta manera de nombrar su casa como una casa quinta revela una representación que transpone dos realidades: la experiencia de su pasado rural y su experiencia actual en la quebrada. De alguna manera, reproduce un fragmento de ruralidad en la ciudad.

Por otra parte, en este relato se utilizan simultáneamente dos palabras opuestas que representan la casa, en un principio la señora Doraliza define su casa como una chosita, haciendo referencia al pasado y al carácter precario de su vivienda y luego la define como una casita quinta el cual es diminutivo de casa quinta, y que se refiere, tal como lo mencionamos anteriormente, a una casa que posee una gran sitio con plantaciones de árboles. Se aprecia en su discurso las transformaciones que ha sufrido la casa, en tanto que construcción evolutiva.

En la mayoría de los relatos recogidos, las representaciones que poseen los habitantes de sus casas tienden a evocar otros lugares. De esta manera, una de las principales características de las representaciones que poseen los habitantes de las quebradas es que un lugar siempre evoca otro lugar. Entre un lugar y otro se establece una co-presencia, el significado de un lugar evoca el sentido de otro lugar. Antoine Bailly (1989) señala que En un entorno histórico y socialmente dado, el individuo construye su propia realidad articulando lo estructural, lo funcional y lo simbólico; (...) el paisaje nos remite a nuestra experiencia existencial; cómo se articulan lo real y lo imaginario en cada lugar (Cit. en Lindón, 2007:9).

Así, esta imagen campestre o rural se ve reforzada con todas las actividades que sucedían y que se desarrollaban antiguamente en la quebrada, donde la vegetación y las fuentes de agua natural, construían esta imagen de un trozo del campo en la ciudad. La señora de la quebrada Las Chanas (HF, mujer 75 años), nos cuenta 
que su casa era una quinta, porque tenían plantaciones de árboles frutales, verduras, flores, incluso tenían vacas y burros. Que el agua de la quebrada era limpia y la utilizaban para el regadío, por medio de unos canales que su padre había construido.

Yo llegue a los 3 años y tengo 75, llegue con mis padres éramos 4 hijos y fuimos 10, aquí jugábamos mucho, esto era una quinta, pero era, ahora ya por lo mismo que han hecho tantas casas y esto de la tierra, la tierra, la tierra, y entonces ya no tenemos agua tampoco para regar porque antes se regaba con el agua de la quebrada, eran aguas limpias ahora no se podría sacar ni una piedra de ahí usted termina toda contaminada de ahí (HF, mujer 75 años, quebrada Las Chanas).

Incluso esta imagen de casa quinta, no sólo la poseen sus habitantes, sino también sus vecinos. El señor de la quebrada Las Chanas (HF, hombre 65 años), dice:

todo eso tiene dueño es una "quinta para allá", todo ese terreno donde están los arboles pertenece a esa gente de esa "casa quinta" que está ahí, tienen hasta allá atrás ellos, hasta la quebrada allá atrás, son propietarios esa familia de allí, si es una quinta eso para atrás, los cabros son varios ellos ahí, la familia (HF, hombre 65 años, quebrada Las Chanas).

Por otra parte la palabra rancho y su diminutivo ranchito, también explicitan esta imagen de casa campestre en la ciudad, pero por el contrario a la casa quinta, que implica un terreno vasto, con una

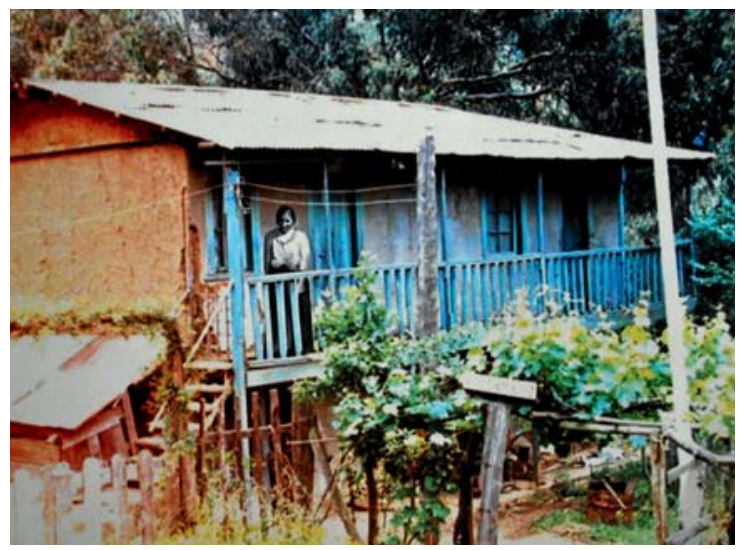

$>$ Figura 5. Antigua fotografía de HF, mujer 75 años, en quebrada Las Chanas. Fuente: Autor.

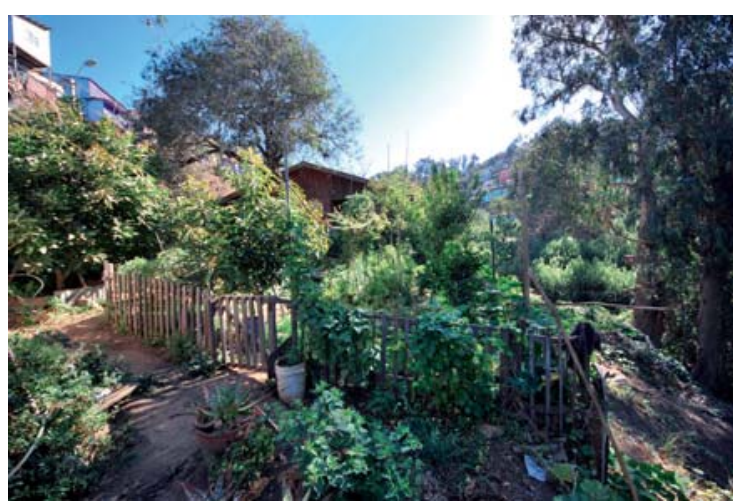

> Figura 6. Fotografía de huerto de HF, mujer 75 años, en quebrada Las Chanas. Fuente: Autor.

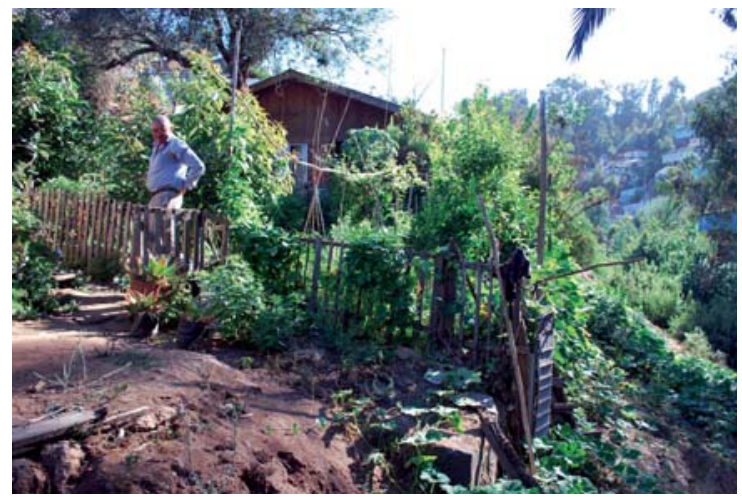

Figura 7. Fotografía de huerto de HF, mujer 75 años, en quebrada Las Chanas. Fuente: Autor.

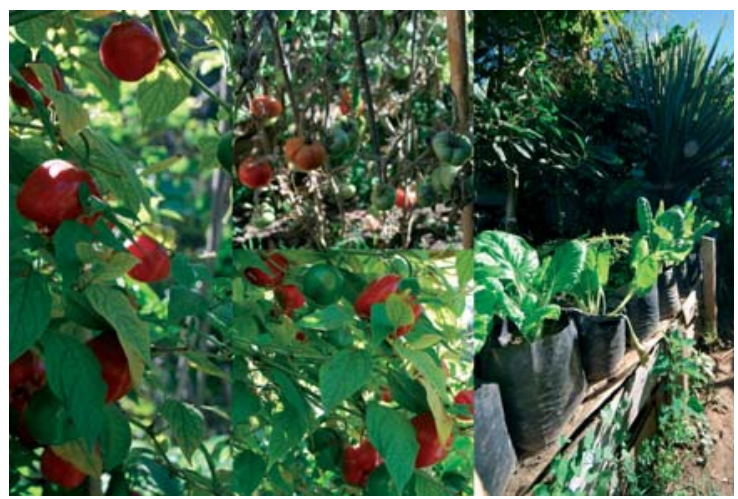

$>$ Figura 8. Fotografía de huerto de HF, mujer 75 años, en quebrada Las Chanas. Fuente: Autor.

gran casa y plantaciones de árboles frutales y huertos; la palabra rancho y/o ranchito, en cuanto a su aspecto formal transmite una imagen de extrema precariedad de la vivienda, y es utilizada por sus propios moradores, porque sienten que viven en una casa a medio hacer y medio abierta, sin terminar.

este es mi ranchito. (HF, mujer 71 años, quebrada El Litre)

Aquí llegamos a un "rancho" prácticamente, porque no era una casa, habian animales, nosotros, toda la familia de él, llegaron le dieron cama y todo, y para nosotros no alcanzaron las camas, asi que nos dieron un pedazo en la cocina y ahí dormíamos en la cocina tirábamos la ropa de cama en el suelo y ahí dormíamos (HF, hombre 80 años quebrada Las Cañas).

En el caso de las quebradas de Valparaíso, cuando estas comenzaron a ser ocupadas mediante el hábitat informal a mediados del siglo XIX, la vivienda contemplaba esta doble condición, de dar lugar y cobijo a hombres y a animales. Evidentemente cada uno en recintos diferenciados, sin embargo, esta imagen campestre se arraigó en el imaginario colectivo, no sólo de sus propios moradores, sino también de quienes desde fuera percibían esta forma evocativa del mundo rural de habitar, la cual incluso en algunas quebradas se mantiene hasta hoy en día. Con respecto a ello una señora de la quebrada las Cañas (HD, mujer 37 años) nos relata lo siguiente:

Antes de vivir aquí nosotros estuvimos viviendo en San Roque (cerro), entonces mi marido tenía animales y donde vivía no podía tener animales, entonces él se vino para acá, como él es nacido y criado acá, su mamá vive allá
58 > Revista Márgenes No 13 Vol. 10 > Diciembre 2013: 49-61 Facultad de Arquitectura > Universidad de Valparaíso
$>$ ISSN electrónico 0719-4436
> ISSN impreso 0718-4034 

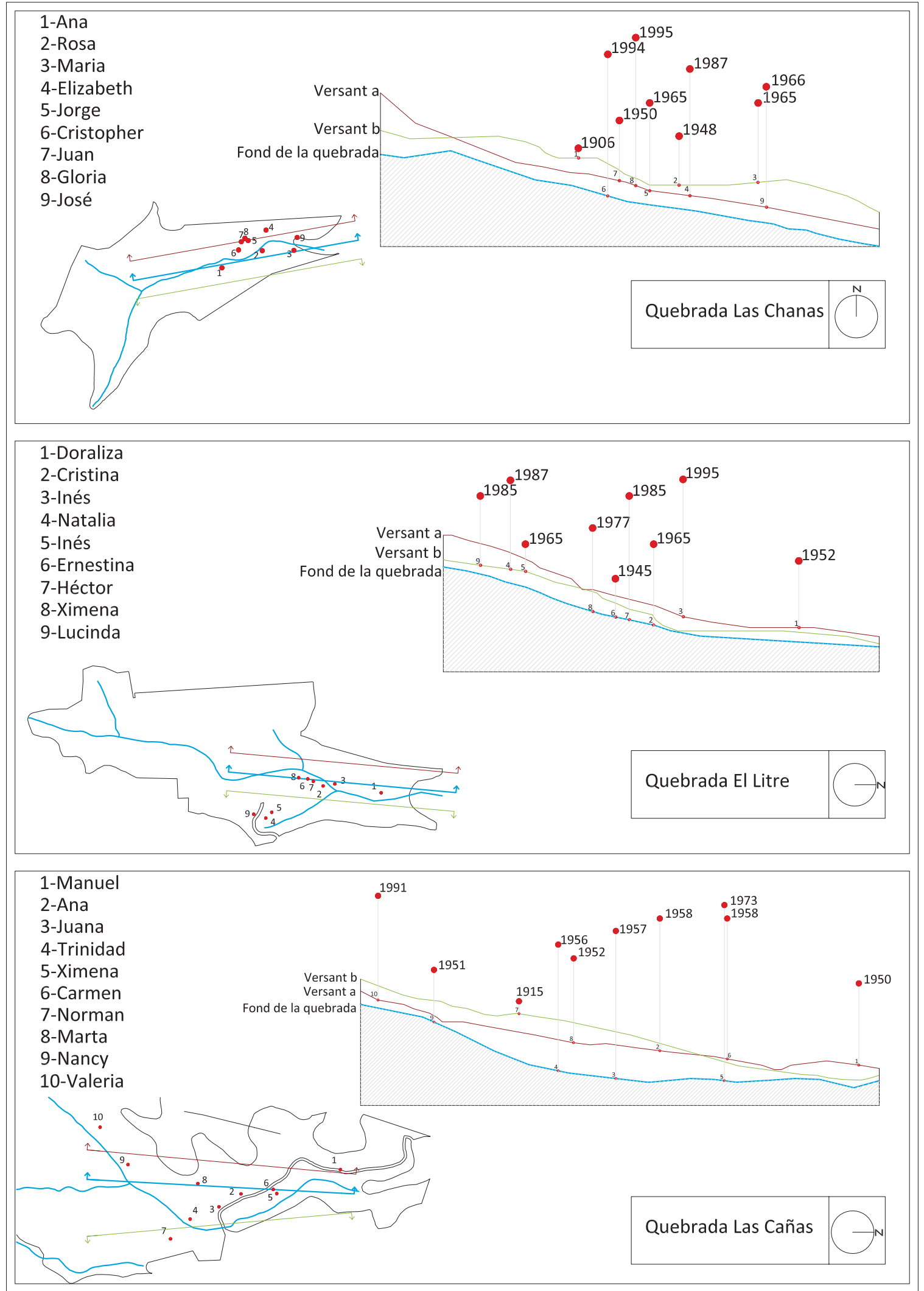

$>$ Figura 9. Gráfico que representa la localización y secuencia del arribo de los habitantes entrevistados en tres quebradas (Las Chanas, El Litre y Las Cañas). Archivos: Autor. 


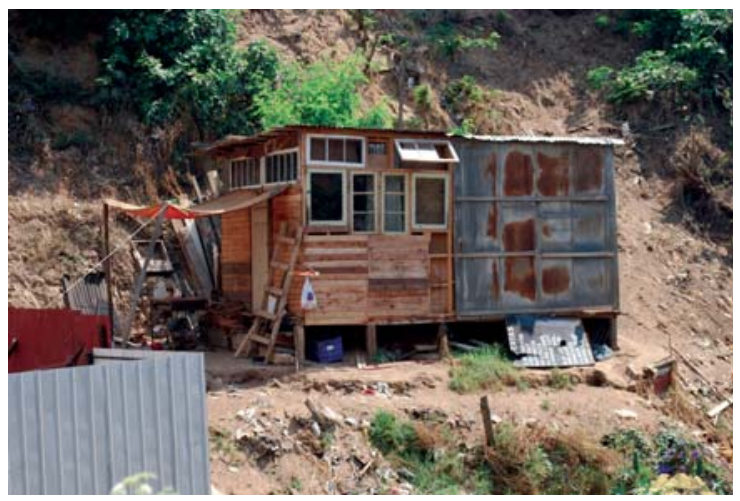

> Figura 10. Ranchos en las quebradas Las Cañas y Francia. Archivos: Autor.

en la esquina. Entonces se buscó este pedazo de terreno lejos también del sector de las casas, por lo mismo, porque él tiene animales, tenemos chanchos y caballos, para atrás está lleno de corrales, son los animales que están ahí, chanchos, caballos, chivos, y ayer trajo un conejo.[...] de repente, en una fiesta el faena uno para la casa, pero los tiene para venderlos [...] acá hay gente que les gustan los animales del sector $y$ andan buscando un chancho, y mi marido se los vende y se los llevan, por ejemplo en un tiempo criamos gallinas, teníamos más de 100 gallinas (HD, mujer 37 años, quebrada Las Cañas).

De esta forma, al momento de la construcción de la casa no sólo se contempla el lugar para la familia, sino que también que se construye el cobijo para los animales. De esta manera el rancho define un lugar de habitación, pero también el lugar donde se desarrolla una actividad económica que otorga una parte del sustento a la familia. Ya que los animales se crían para ser vendidos y solo ocasionalmente para el consumo familiar.

Por otra parte, este término posee un carácter peyorativo, cuando es utilizado por alguien ajeno al lugar y que mira desde afuera el fenómeno de una toma. Utilizando su conjugación rancherío para describir a un grupo de casas de origen informal y de estética precaria. Lo lógico sería llamarlos caserío ya que este sustantivo define un conjunto de casas.

\section{CONCLUSIÓN}

Se concluye que la recomposición de la ruralidad en el medio urbano en Valparaíso, se evidencia en las quebradas de Valparaíso cuando sus habitantes utilizan de forma recurrente los diminutivos de cada una de las acepciones que hemos revisado en la investigación, casa quinta o casita quinta, rancho o ranchito y choza o chosita, al mismo tiempo de hacer referencia al tamaño de la vivienda, también expresan el afecto que sienten sus moradores por el lugar que habitan, puesto que el sufijo ita o ito, expresan pertenencia y poseen un valor afectivo.

Complementariamente, las representaciones que poseen los habitantes de las quebradas de Valparaíso en relación a sus casas, se identificó que el grupo más presente, fue el de las representaciones asociadas a una imagen campestre. Donde se identificaron dos extremos la casa quinta que expresa una imagen de confort en armonía con la naturaleza y su explotación agrícola, y por otra parte la del rancho y la choza que hacen referencia a una estética precaria y a formas inconclusas de casa, como lugares a medio hacer, abiertos, es decir, sin terminar.
De esta forma se descubre que la casa de la quebrada, mantiene esta doble condición de lugar de habitación y de producción, constituyéndose como una de las tantas tipologías que aparecen desde la informalidad, las cuales relevan un fuerte trasfondo popular, que entre otros, hace referencia al éxodo rural a la ciudad de Valparaíso que se produjo desde la segunda mitad del siglo XIX.

El Hábitat autoconstruido presente en las quebradas de Valparaíso es visto como un éxito familiar resultante de sus propios esfuerzos. Los habitantes consideran que el trabajo, el tiempo y los recursos invertidos son más altos que cualquier deficiencia y/o precariedad que presentan sus viviendas, por ello se concluye que cualquier tipo de intervención urbana, debiese incluir este tipo de lógicas e investigar de forma integral la complejidad socio espacial que alberga la autoconstrucción.

\section{BIBLIOGRAFÍA}

AGIER M. (2009) Esquisses d'une anthropologie de la ville, Lieux, situations, mouvements. Louvain-la-Neuve, Belgique, Bruylant-Academia S.A.

(1999) L'invention de la ville, Banlieues, township, invasions et favelas. Paris, France, Éditions des Archives Contemporaines, Une pensée d'avance.

AHUMADA J., LÓPEZ P., QUINTANA C. (2003) Catastro campamentos región metropolitana CIS 2003. Revista semestral centro de investigación social de un techo para Chile e Infocap. Año $2 \mathrm{~N}^{\circ} 3$, páginas 24-29.

BACHELARD G. (1957) La poétique de l'espace. Paris, Quadrige/PUF.

BERENSTEIN-JACQUES P. (2001) Les favelas de Rio, un enjeu culturel. Paris, France, L'Harmatan.

BERTAUX D. (2010) L'enquête et ses méthodes, le récit de vie. Paris, Francia, Armand Colin.

BOLívAR T. (1995) Hacedores de ciudad. Caracas, Venezuela.

BORJA I SEBASTIÁ J. (2003) La ciudad conquistada. Madrid, España, Alianza Editorial S.A.

BUSQUET I GRAU J. (1999) La urbanización marginal. Barcelona, España, Edicions UPC.

DAVIS M. (2007) Planeta de ciudades miseria. Madrid, España, FOCA ediciones y distribuciones generales S. L.

DE CERTEAU M. (1990) L'invention du quotidien, 1 art de faire. Paris, Folio Essais.

DI MÉO G. (1998) Géographie sociale et territoires. Paris, France, éditions Nathan.

FERNANDES E. (2008) Consideraciones generales sobre las políticas públicas de regularización de asentamientos informales en América latina. Revista Eure, vol. 34, N 102, páginas 25-38.

HARDOY J. E. y SATTERTHWAITE D. (1987) La ciudad legal y la ciudad ilegal. Buenos Aires, Argentina, Grupo editor Latinoamericano S. R. L.

JODELET D. (1984) Représentation sociale: phénomènes, concept et théorie. Dans: Moscovici, Serge (ed.) Psychologie sociale, páginas 364-384. Paris: Presses Universitaires de France.
60 > Revista Márgenes № 13 Vol. 10 > Diciembre 2013: 49-61 Facultad de Arquitectura > Universidad de Valparaíso
$>$ ISSN electrónico 0719-4436 > ISSN impreso 0718-4034 
(2011) La representación social: fenómenos, conceptos y teoría Dans: Moscovici, Serge (ed.) Psicología social, II pensamiento y vida social, Psicología social y problemas sociales, páginas 469-494. Barcelona: Ediciones Paidós.

KAPSTEIN LÓPEZ P. (2004) Análisis de asentamientos precarios en Valparaíso y su incidencia en el crecimiento urbano, Revista INVI, Vol. 18 N049, páginas 83-101.

LEFEBVRE H. (2000) La production de l'espace. $4^{\text {ta }}$ edición. Paris, France, Ed. Anthropos.

LINDÓN A. (2000) La espacialidad como fuente de las innovaciones de la vida cotidiana. Hacia modos de vida cuasi fijos en el espacio. Dans: Lindon, Alicia (ed.) La vida cotidiana y su espacio-temporalidad, páginas 187-210. Barcelona: EI Colegio Mexiquense-CRIM-Anthropos de Barcelona.

(2002) La construcción social del territorio y los modos de vida en la periferia metropolitana. Revista Territorios, $\mathrm{N}^{\circ}$ 7, páginas 27-41.

(2005) "El mito de la casa propia y las formas de habitar". Scripta Nova Revista electrónica de geografía y ciencias sociales, Vol. IX, núm. 194.

(2006) La espacialidad de la vida cotidiana. Hologramas socio-territoriales de la cotidianeidad urbana. En Nogué, Joan \& Romero, Joan (eds.) Las otras geografías, páginas 425-446. Valencia: Tirant lo Blanch.

(2007) El constructivismo geográfico y las aproximaciones cualitativas. Revista de Geografía Norte Grande, $N^{\circ} 37$, páginas 5-21.

(2007) La ciudad y la vida urbana a través de los imaginarios urbanos. EURE (Santiago), Vol. 33, 99, páginas 7-16.

(2007) La construcción social de los paisajes invisibles del miedo. En Joan, Nogué (ed.) La construcción social del paisaje, paginas 219-242. Madrid: editorial biblioteca nueva S. L.

(2007) Los imaginarios urbanos y el constructivismo geográfico: los Hologramas espaciales. EURE (Santiago), Vol. $33, N^{\circ} 99$, páginas 31-46.

MINISTERIO DE VIVIENDA, GOBIERNO DE ESPAÑA (2010) Las tomas de tierras urbanas en Latinoamérica hoy. Madrid, España, Ministerio de Vivienda Secretaría General Técnica, Centro de Publicaciones.

NEGURA L. (2006) "L'analyse de contenu dans l'étude des représentations sociales", SociologieS [En Línea], Théories et recherches, http://sociologies.revues.org/993

MOScoVICI S. (1984) Introduction. Dans: Moscovici, Serge (ed.) Psychologie sociale, páginas 5-22. Paris: Presses Universitaires de France.

(2011) Introducción Dans: Moscovici, Serge (ed.) Psicología social, Il pensamiento y vida social, Psicología social y problemas sociales, páginas 17-40. Barcelona: Ediciones Paidós.

RAPOPORT A. (1972) Pour une anthropologie de la maison. Paris, Dunod.

(2003) Cultura, arquitectura y diseño. Barcelona, Edicions UPC.
TURNER J. F. C. (1977) Vivienda, todo el poder para los usuarios. Madrid, España. Herman Blume Ediciones.

\section{NOTAS}

1 Este Artículo es producto de la tesis doctoral Habitat informel dans les quebradas de Valparaíso dynamiques d'appropiation, financiada por CONICYT Becas-Chile.

2 Unidad urbana: una unidad de análisis, representada en una porción del espacio urbano que ha construido y habita una comunidad, por tanto la reconoce y apropia culturalmente como su territorio y lucha por su mejoramiento y consolidación. Es la unidad de identificación de la ciudad hacia el barrio y de sus habitantes hacia este, entendida como resultado de la articulación de elementos físicos, sociales, económicos, políticos y culturales. (Guarín Cobos, 2003:101)

3 Una familia extendida (Familia extendida) para el Censo Nacional Chile Glosario es un tipo de familia basada en los lazos consanguíneos a mucha gente. Incluye padres, hijos, abuelos, tíos, tías, sobrinos, primos y otros. http:// www.bcn.cl/ecivica/ concefamil

4 Cabe señalar que estas personas son elegidas democráticamente por el voto y son de carácter voluntario.

5 En algunos casos el sufijo ita o ito toma la forma -ecito -ececito -cito. (Solecito, piececito, corazoncito, mujercita (R.A.E, 2011). La palabra casita proviene del sustantivo casa (casa) con el sufijo ita. El diminutivo ita o ito, (del latín. vulg. - îttus) contiene un valor de pequeñez y afectivo.

6 http://lenma.rae.es/drae/?val=rancho

7 Centre National de Ressources textuelles et lexicales. http:// www.cnrtl.fr/ definition/chalet
Revista Márgenes N 13 Vol. 10 > Diciembre $2013>61$ Facultad de Arquitectura > Universidad de Valparaíso 